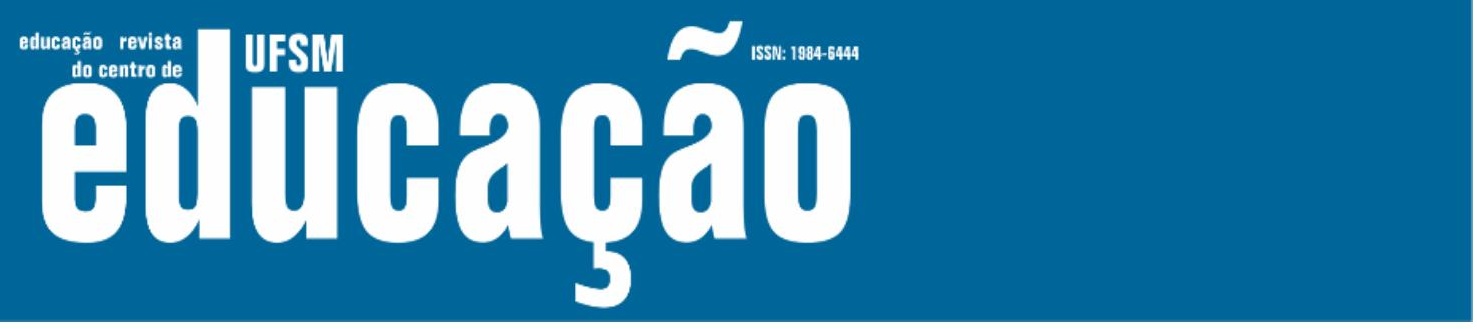

ISSN: 1984-6444 | http://dx.doi.org/10.5902/1984644440380

\title{
Professores iniciantes em cursos de licenciatura: história de vida, formação e desenvolvimento profissional
}

Teachers beginning in undergraduate courses: life history, training and professional development

\author{
Sebastião Silva Soares \\ Professor doutor na Universidade Federal do Tocantins. Palmas, Tocantins, Brasil. \\ sebastiaokenndy@yahoo.com.br - http://orcid.org/0000-0002-5572-014X \\ Selva Guimarães \\ Professora Titular na Universidade de Uberaba. Uberlândia, Minas Gerais, Brasil \\ selva.guimaraes@uniube.br - http://orcid.org/0000-0002-8956-9564
}

Recebido em 04 de outubro de 2019

Aprovado em 08 de julho de 2020

Publicado em 31 de janeiro de 2021

\section{RESUMO}

O trabalho teve por objetivo compreender a constituição das trajetórias formativas de professores formadores iniciantes em instituições federais de Educação superior na região Norte do Brasil. A abordagem metodológica foi vinculada ao campo da história oral de vida. Os colaboradores foram seis formadores, em fase inicial da carreira docente na universidade, atuantes em cursos de licenciatura em História, Pedagogia e Educação do Campo, de duas instituições de Educação superior. Empregou-se a entrevista narrativa, abordando a história de vida, a formação e o desenvolvimento profissional dos professores. Para a análise das narrativas, utilizou-se uma leitura Interpretativa-Compreensiva. As experiências narradas revelaram que a fase inicial na docência universitária foi compreendida pelos professores como um tempo de validação dos aprendizados apreendidos no decorrer da trajetória formativa de vida e profissional. Compreendeu-se no estudo que a constituição das trajetórias formativas dos formadores iniciantes atuantes nos cursos de licenciatura estava diretamente relacionada às histórias de vida, à formação e à profissão.

Palavras-chave: Histórias de Vida; Trajetórias Formativas; Professor Formador Iniciante. 


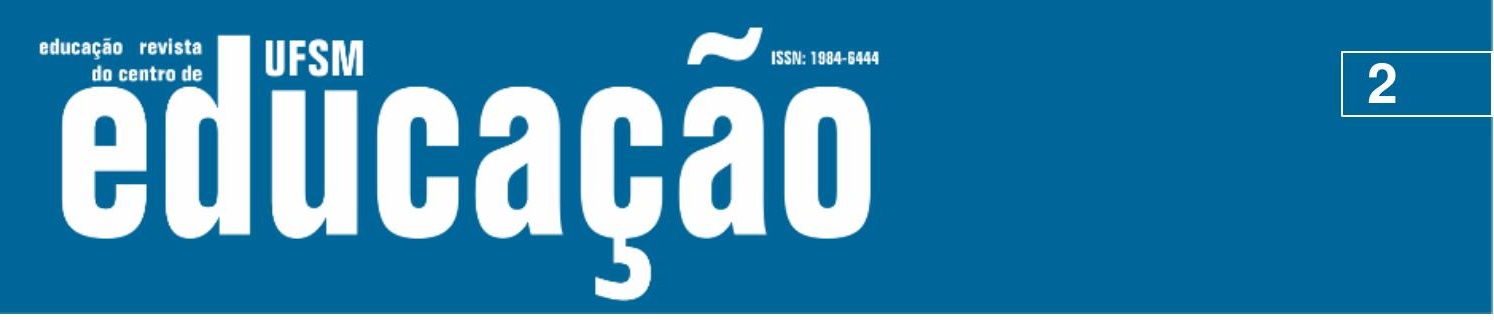

ISSN: 1984-6444 | http://dx.doi.org/10.5902/1984644440380

\section{ABSTRACT}

The goal of this work was to understand how is constituted the formative trajectories of beginning teacher educators in federal institutions of Higher Education in the Northern region of Brazil. The methodological approach was linked to the field of oral life story. The collaborators were six teacher's trainers, in the initial phase of the teaching career in the university, acting in teaching training courses of Pedagogy, History and Field Education, of two institutions of Higher Education. The narrative interview was used, addressing teachers' life story, training and professional development. For the narrative analysis we used an Interpretative-Comprehensive reading. The experiences reported revealed that the initial phase in university teaching was taken by the professors as a time of validation of the learning apprehended during the formative life and professional trajectory. It was understood that the formation of the beginning teacher in the teaching training courses studied was directly related to life experiences.

Keywords: Life Stories; Formative trajectories; Teacher Trainer Beginner.

\section{Introdução}

Os primeiros anos da carreira docente são considerados fundamentais na construção da identidade profissional ${ }^{1}$ do professor. É uma fase de mudanças de papéis em que a pessoa vivencia a transição de discente para a função de professor (GARCIA, 1999; DOMÍNGUES; ESTEPA; GARCIA, 2019). É o início de um ciclo marcado por sentimentos de alegria, conquistas, desafios e medos. As memórias ${ }^{2} \mathrm{e}$ as experiências ${ }^{3}$ narradas por professores, nesse momento da carreira docente, demonstram múltiplas dimensões, sentimentos como a sensação de dúvida, insegurança inabilidade para organização didática e pedagógica da sala de aula.

Estudos e pesquisas, tanto em âmbito internacional quanto nacional como, (IMBERNÓN; SHIGUNOV NETO; FORTUNATO, 2019) evidenciam que a inserção/iniciação à docência pode ser uma travessia, (tempo e espaço) de descobertas, encantos e choque da realidade para o professor iniciante, pois o docente busca, nesse início do exercício profissional, validar os conhecimentos obtidos na vida escolar e acadêmica, ao assumir uma sala de aula e demais funções que são the atribuídas. 


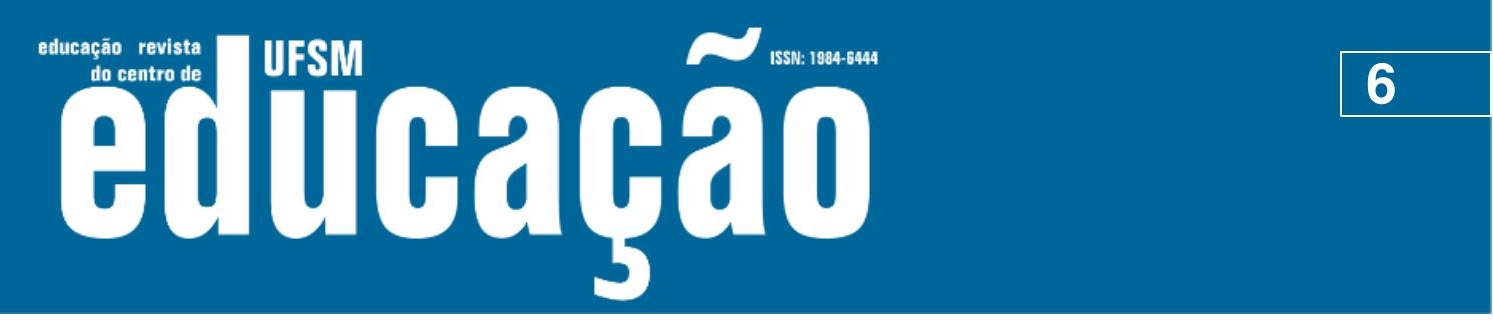

ISSN: 1984-6444 | http://dx.doi.org/10.5902/1984644440380

As entrevistas orais foram elaboradas em torno de questões que emergiram do tema em estudo, como trajeto pessoal, formação escolar e acadêmica, desenvolvimento profissional, saberes docentes e prática pedagógica.

Após o registro das narrativas orais, foi realizada a transposição do texto oral para o escrito a partir dos referenciais metodológicos da história oral (GUIMARÃES, 2006). A análise interpretativo-compreensiva foi utilizada na produção e organização das narrativas. De acordo com Souza (2004, p. 120), essa abordagem considera "[...] o tempo de lembrar, narrar e refletir sobre o vivido". Os colaboradores atuam em duas Universidades Federais em Cursos de Licenciatura em Pedagogia, História e Educação do Campo. Nesse texto foram identificados com pseudônimos, no sentido de garantir a privacidade e os princípios éticos da pesquisa, conforme apresentado na biografia a seguir:

Cássia - é natural do estado do Paraná, 32 anos, é casada e possui um filho. Licenciou-se em História pela Universidade Estadual do Oeste do Paraná (UNIOESTE) e cursou o mestrado na área da História pela mesma instituição, além de ter trabalhado no contexto do ensino público no Paraná. No momento da pesquisa, cursava o doutorado em História pela Universidade Federal de Uberlândia (UFU). É docente do curso de História.

Clarissa - é de Santa Catarina, tem 33 anos de idade e é casada. Graduouse em Pedagogia pela Universidade Estadual do Rio Grande do Sul (URGS), possui doutorado em Educação pela Universidade Federal do Rio Grande do Sul (UFRGS) e mestrado na mesma área Educação pela Universidade Regional do Noroeste do Estado do Rio Grande do Sul (UNIJUí). Já trabalhou como professora e coordenadora na Educação Básica. É docente do curso de Educação do Campo.

Eliana - nasceu em Rondônia, tem 32 anos e é casada. É bacharel em Engenharia Agrônoma pela Universidade Luterana do Brasil (ULBRA), tem doutorado em Ciências do Solo pela Universidade Federal Rural de Pernambuco (UFRPE) e desenvolveu o mestrado pela Universidade Federal do Acre, na área da Agronomia. É professora do curso de Educação do Campo. Não possuía, no momento de realização deste estudo, experiência como docente na Educação Básica.

Elisa - é natural do Rio Grande do Sul, possui 48 anos de idade, é casada e mãe de quatro filhos. Cursou o mestrado em Educação pela Universidade de Pelotas (UFPel). Formou-se em Pedagogia pela Universidade Católica de Pelotas (UCPel) e em Geografia pela UFPel. A formadora possui práticas profissionais na Educação Básica e Educação superior - inclusive, é professora do curso de Pedagogia.

Mariana - é do estado de Minas Gerais, possui 34 anos e é casada. Desenvolveu estudos acadêmicos em Artes e Psicologia pela Universidade Federal de Juiz de Fora (UFJF), cursou o mestrado em Artes pela mesma instituição e possui um segundo mestrado na área de Estudos Literários pela 


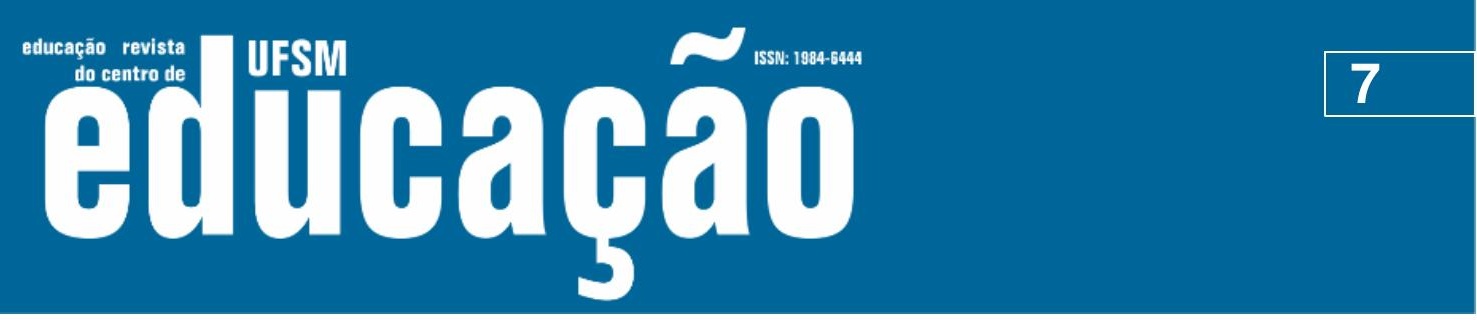

ISSN: 1984-6444 | http://dx.doi.org/10.5902/1984644440380

Universidade Federal de Minas Gerais (UFMG). A formadora tem experiência profissional no contexto da educação informal, atuando em Organizações não Governamentais (ONGs), e foi professora substituta na Educação superior. É docente do curso de Educação do Campo.

Ronaldo - é natural do estado da Bahia, possui 53 anos, é casado e tem quatro filhos. Formou-se em Música pela UFRGS e em Educação Física pela Universidade Católica do Salvador (UCSal). É professor do curso de Educação do Campo. Ele possui experiência profissional como docente na educação básica e Educação superior.

Delineando os perfis dos formadores ${ }^{9}$ por meio de uma leitura cruzada, realçamos que a oportunidade de escutar os professores iniciantes possibilitou criar um mosaico de marcadores da vida e profissional dos docentes. Buscou-se não apenas compreender a prática pedagógica, como também registrar as maneiras como se constituem e (re)constroem significados das próprias trajetórias formativas e experiências, ao atuarem nos cursos de licenciatura.

Em contribuição, D’Avila e Sonneville (2012) afirmam que investigar histórias de vida caracteriza a valorização do sujeito da pesquisa, pois o objetivo do estudo é compreender e registrar as vozes dos indivíduos que, naquele contexto, são autores e personagens da própria história, o que indica mais do que a narração dos acontecimentos. As narrativas assumem um caráter de formação e investigação, pois, no exercício do reviver as lembranças do passado, o sujeito tem condições e oportunidade de (re)construir saberes, onde o passado faz-se presente.

Nesses termos, a pesquisa se justifica pela relevância social e científica do território ainda restrito e ocupado pelo tema da docência na Educação superior, comparativamente aos demais estudos sobre a formação de professores, conforme observado nos estudos de Cunha (2014); Silva (2014) e Nunes (2011), dentre outros. Ao estudar histórias de vida de formadores iniciantes no contexto dos cursos de licenciatura, a partir da história de vida almejamos construir conhecimentos que auxiliem na promoção e valorização do docente da Educação superior, especialmente de formadores de professores, no início da carreira, na universidade. Na próxima seção, analisamos os elementos constitutivos de vida, formação e desenvolvimento profissional dos docentes da pesquisa. 


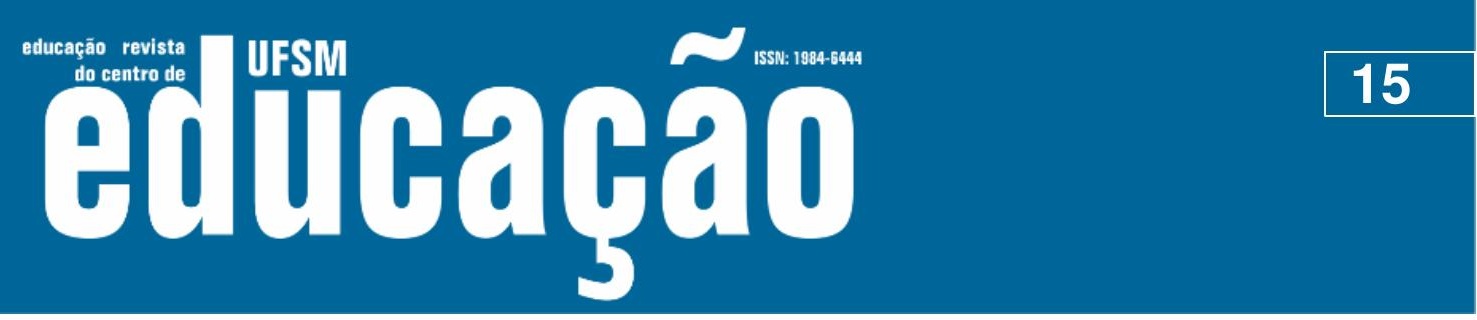

ISSN: 1984-6444 | http://dx.doi.org/10.5902/1984644440380

Sinto um pouco disso aqui na instituição, porque há uma carência de leitura por parte dos alunos. Mas, entra nessa análise uma questão que é contraditória e complexa, relacionada ao perfil dos acadêmicos que são trabalhadores, fato que precisamos levar em consideração (Professora Cássia).

Tento deixar essas coisas bem claras, pois entendo que é a partir do entendimento sobre formas de avaliação que ocorrem os problemas entre alunos e professores na sala de aula (Professora Eliana).

Sobre a minha relação com os alunos em sala de aula, acredito que seja tranquila. Às vezes, saio com a cabeça "desse tamanho", com raiva (Professora Elisa).

Sobre o meu relacionamento com os alunos, assim que cheguei, foi muito bom. Depois, você vai entrando no ritmo e, às vezes, eles começam a abusar demais (Professora Mariana).

Em outro ângulo, os relatos expressaram diversas facetas que compõem a tessitura da docência universitária como atividade social e complexa, como a questão da inclusão, políticas de acessibilidade, a dimensão multicultural nas instituições formativas, conforme demonstrou Cerezer (2015), em especial, as fragilidades formativas das propostas curriculares de cursos de formação de professores.

\section{Ser professor iniciante na universidade: desafios, dilemas e possibilidades}

Nos relatos dos professores ressoaram sentidos e significados que assinalaram a fase inicial na docência universitária como um tempo de descobertas, alegrias, entusiasmo, conquistas, dilemas e dificuldades (BOZU, 2010). No começo da docência superior, os professores vivenciaram sentimentos de identificação ou ressignificação da profissão professor. É possível refletir que a fase inicial da docência na Educação superior, por parte dos formadores, ultrapassou os dilemas característicos dos professores iniciantes no âmbito acadêmico (RUIZ, 2008).

Os desafios e as possibilidades do começo da docência universitária desvelaram olhares singulares e coletivos que, ao mesmo tempo, aproximaram e se distanciaram da constituição da docência universitária, seja pelas lacunas da formação, pela realidade e pelas condições de trabalho dos professores. 


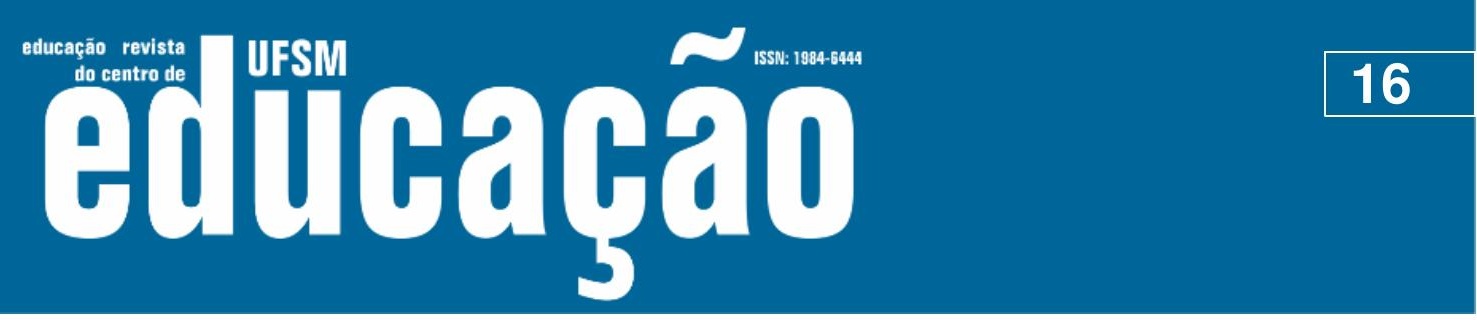

ISSN: 1984-6444 | http://dx.doi.org/10.5902/1984644440380

Trabalhava um pouco com a pesquisa e a história da África, conteúdo último que não havia estudado no meu processo de formação. [...] acredito que outro desafio aqui, para mim, não sei se também é para os outros, é justamente a precária infraestrutura da universidade - o curso é novo, de 2009, e vivenciamos processos de greve (Professora Cássia).

A narrativa da colaboradora ecoou marcas e significados da fase inicial da docência universitária vivenciada por muitos professores, particularmente a necessidade de completar a carga horária de trabalho, a habilidade pedagógica e de conhecimento em determinadas áreas/temáticas, e solidão pedagógica (CUNHA, 2014). De acordo com a autora citada, muitas dificuldades relatadas pelos professores iniciantes na Educação superior correspondem às responsabilidades pedagógicas e administrativas, diante das quais nem sempre estão aptos ou habilitados a assumir e resolver.

Outro dilema narrado pela professora formadora iniciante concerne aos problemas estruturais da instituição de ensino e às condições de trabalho, como laboratórios e uma biblioteca universitária adequada. Tal questão foi confirmada pelos demais professores, sobretudo por conta da escassez de recursos, observada nas instituições em virtude das reformas financeiras e de cortes de recursos, problemas estruturais, sobrecarga de trabalho e demandas não relacionadas ao ensino, à pesquisa e à extensão.

Diferentemente de Cássia, a narrativa de Clarissa demonstrou desafios iniciais na docência universitária, como a habilidade e domínio de turmas. Este último aspecto se articula às dificuldades na organização e no desenvolvimento pedagógico, pois enfrentou empecilhos no processo de ensino e aprendizagem ao propor determinado exercício em classe. Ademais, a imersão na cultura organizacional da universidade foi caracterizada por ela como uma instância burocrática e hierarquizada.

\footnotetext{
Em relação aos desafios e dificuldades encontradas no início da carreira, na Educação superior, posso destacar a questão do domínio de turma, porque, como estudei em uma turma que era formada por pessoas de movimentos sociais e estou na Educação do Campo, eu tinha certa ilusão de que a experiência seria parecida. E não é! Não sei se é pela região, mas acho que não. [...] No primeiro semestre, encontrei dificuldade na explicação do conteúdo: por exemplo, encaminhei o trabalho para a classe e os alunos não compreenderam o que era para realizar (Professora Clarissa).
} 


\section{تilloapẫ}

ISSN: 1984-6444 | http://dx.doi.org/10.5902/1984644440380

profissional do início de ingresso/inserção à docência a partir da sua história de vida, pois "a trajetória profissional constitui-se como substrato do processo de contextualização da docência, revelando os significados e os sentidos da profissão" (BOLZAN; POWACZUK, 2019, p. 76).

Em outra análise, os professores expressaram diversas expectativas sobre o Curso e o desenvolvimento do ofício de formadores. Há preocupação da maioria em contribuir para a formação dos estudantes e o desenvolvimento social, enquanto outros expuseram os dilemas e as incertezas da docência universitária. Pelos relatos, vimos que as expectativas dos colaboradores com o curso de atuação e a função de formadores convergiam para a necessidade de ampliação e revisão das práticas pedagógicas realizadas no âmbito da docência universitária.

Os docentes desejavam construir um movimento de busca permanente no desenvolvimento da carreira universitária, embora a maioria dos professores reconhecesse que tal processo apresenta limitações e incertezas, principalmente no tocante à redução dos investimentos públicos no campo do ensino e da pesquisa nas instituições, evidenciaram expectativas positivas no desenvolvimento pessoal e profissional de si e dos outros.

\section{Considerações finais}

Os relatos dos professores evocaram experiências produzidas nas relações familiares, sociais e profissionais. Por meio do exercício da memória, nos levaram a compreender a infância como uma fase significativa na constituição da personalidade. Notamos que o interesse pela docência por parte dos colaboradores foi incentivado por aspectos como espaço de vivência, inserção no mercado de trabalho e a influência de professores marcantes, e não propriamente pela influência familiar.

Verificamos que o processo de escolarização básica foi marcado por necessidades, oportunidades e desafios que entrecruzam suas histórias de vida. As narrações destacaram os conteúdos aprendidos, as dificuldades de aprendizagem e as relações com professores e colegas. Vale salientar que, embora alguns deles não 


\section{Tusm

ISSN: 1984-6444 | http://dx.doi.org/10.5902/1984644440380

- Criar políticas institucionais de formação e desenvolvimento profissional dos professores de modo permanente, principalmente para os formadores iniciantes, tanto presencial quanto a distância com plataformas de aprendizagem;

- Ampliar ações formativas aos professores a partir das suas necessidades de formação frente aos desafios da docência universitária e temas geradores de debates;

- Estimular e fortalecer a criação de espaços colaborativos entre docentes e discentes, no sentido de fortalecer a relação dialógica professor-aluno; por meio de fóruns (presencial e on-line), rodas de conversa, comunidades de aprendizagem mediadas por práticas colaborativas dos Colegiados de curso, Núcleo Estruturante (NDE), Projeto Pedagógico Institucional (PPI), dentre outros;

- Desenvolver e ampliar as políticas institucionais existentes de acolhimento e acompanhamento psicossocial aos professores iniciantes, em particular de formadores de professores, em razão do deslocamento territorial, bem como a perda dos vínculos familiares e sociais frente às condições de trabalho que enfrentam; com apoio de equipe multiprofissional.

- Articular a criação de redes de aprendizagem entre a universidade e o espaço escolar, como ambientes de formação permanente para os formadores, professores da educação básica e futuros professores; dentre as quais destacamos a socialização dos membros em programas de valorização à docência como o Programa Institucional de Bolsa de Iniciação à Docência (PIBID) e o Residência Pedagógica.,

- Fortalecer processos formativos que integram a unidade ensino, pesquisa, extensão e gestão no desenvolvimento profissional docente;

- Oferecer melhores condições de trabalho aos formadores de professores, no âmbito pedagógico, quanto na cultura organizacional; 


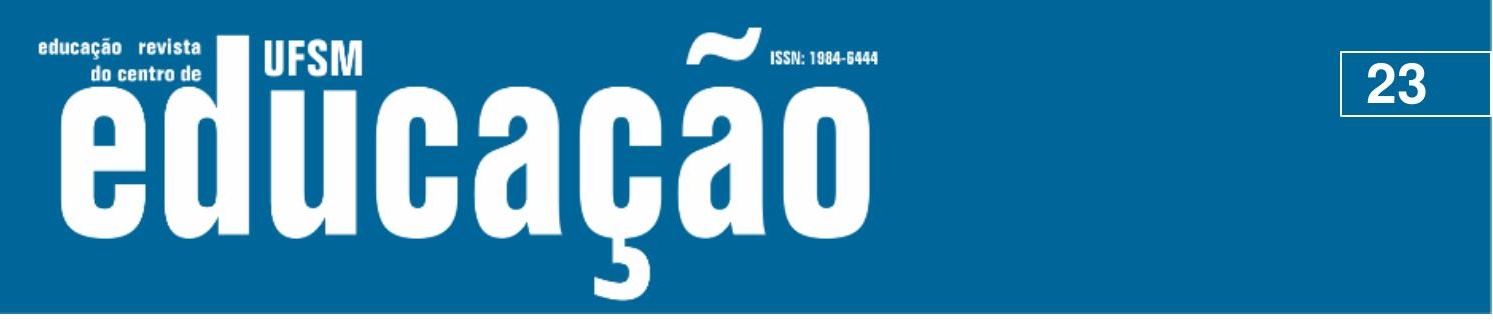

ISSN: 1984-6444 | http://dx.doi.org/10.5902/1984644440380

2014. Tese (Doutorado em Educação) - Universidade Federal de São Carlos, São Carlos, 2014.

D’ÁVILA, Cristina Maria.; SONNEVILLE, Jacques. Trilhas percorridas na formação de professores: da epistemologia da prática à fenomenologia existencial. In: VEIGA, IIma Passos Alencastro.; D'AVILA, Cristina Maria. (Orgs.). Profissão docente: novos sentidos, novas perspectivas. Campinas: Papirus, 2012, p. 23-44.

DOMÍNGUES, Carmen Gallego.; ESTEPA, Paulino Murillo.; GARCIA, Carlos Marcelo. ALÉM DAS DISCUSSÕES ONLINE: aspectos cognitivos, sociais e de formação no processo de indução docente. Currículo sem Fronteiras, v. 19, n. 1, p. 97-112, jan./abr. 2019.

DOMINICÉ, Pierre. O processo de formação e alguns dos seus componentes relacionais. In: NÓVOA, António.; FINGER, Mathias. (Orgs.). 0 método (auto)biográfico e a formação. Natal: EDUFRN, 2010.

DUBAR, Claude. Socialização: construção das identidades sociais e profissionais. São Paulo: Martins Fontes, 2005.

ESTEPA, Paulino Murillo. La socialización del profesorado principiante como elemento de mejora de las organizaciones educativas. In: SOUZA, Flavia Dias de (Org.). Professores principiantes e a inserção à docência: contextos, programas e práticas formativas. Curitiba: UTFPR, 2016, p. 56-77.

FONTANA, Roseli. Como nos tornamos professoras? Belo Horizonte: Autêntica, 2010.

GARCIA, Carlos Marcelo. Formação de professores: por uma mudança educativa. Porto: Porto Editora, 1999.

GATTI, Bernadete Angelina.; BARRETO, Elba Siqueira de Sá. Professores do Brasil: impasses e desafios. Brasília: UNESCO, 2009.

GONZÁLEZ, Alberto Durán. Ser docente na área da saúde: uma abordagem à luz da fenomenologia heideggeriana. 2012. Tese (Doutorado em Saúde Coletiva) Universidade Estadual de Londrina, Londrina, 2012.

GOODSON, Ivor. Dar voz ao professor: as histórias de vida dos professores e o seu desenvolvimento profissional. In: NÓVOA, António. Vidas de professores. Lisboa: Porto Editora, 1992, p. 31-61.

GUIMARÃES, Selva. Ser professor no Brasil - história oral de vida. Campinas: Papirus, 2006.

HUBERMAN, Michael. O ciclo da vida profissional dos professores. In: NÓVOA, António. Vidas de professores. Lisboa: Porto Editora, 1992, p. 31-61. 


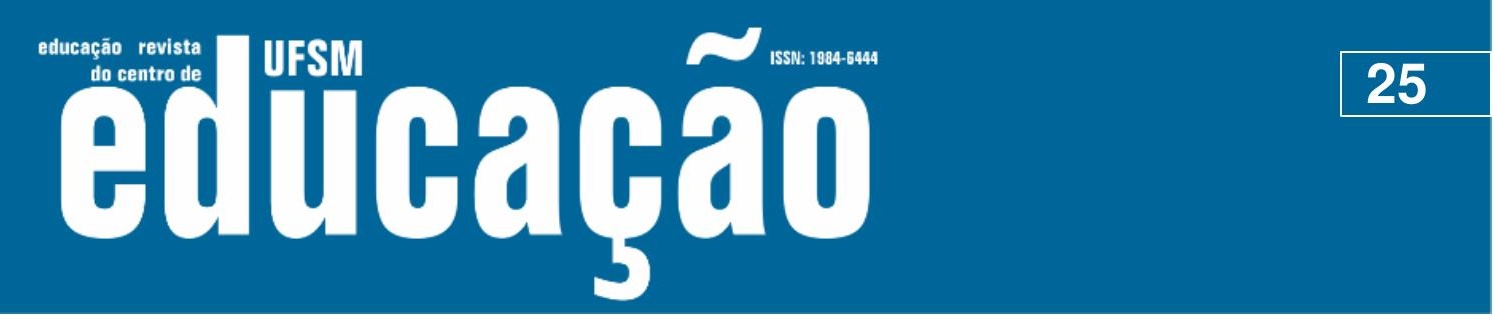

ISSN: 1984-6444 | http://dx.doi.org/10.5902/1984644440380

SILVA, Sandra Regina Lima dos Santos. Professores de Matemática em início de carreira no Ensino Superior. 2014. Tese (Doutorado em Educação) - Pontifícia Universidade Católica de São Paulo, São Paulo, 2014.

SOUZA, Elizeu Clementino de. Conhecimento de si: narrativas do itinerário escolar e formação de professores. 2004. Tese (Doutorado) - Universidade Federal da Bahia, Salvador, 2004.

TARDIF, Maurice. Saberes docentes e formação profissional. Petrópolis: Vozes, 2014.

TOLEDO, Roberto. De não-professor a professor: uma reflexão sobre a construção da identidade profissional de professores de Cursos Superiores de Formação Tecnológica. 2011. Dissertação (Mestrado em Educação) - Universidade de São Paulo, São Paulo, 2011.

VEIGA, IIma Passos Alencastro.; QUIXADÁ VIANA, Cleide Maria. Formação de professores: um campo de possibilidades inovadoras. In: VEIGA, IIma Passos. Alencastro.; SILVA, Edileuza Ferreira da (Orgs.). A escola mudou: que mude a formação de professores! Campinas: Papirus, 2012.

This work is licensed under a Creative Commons Attribution-NonCommercial 4.0 International (CC BY-NC 4.0)

\section{Notas}

\footnotetext{
${ }^{1}$ Partimos da ideia que a construção da identidade docente "é baseada numa revisão constante dos significados sociais da profissão, da revisão das tradições, como também das práticas já consagradas” (PIMENTA, 2002, p. 19).

${ }^{2}$ Segundo Bosi (1994, p. 55), consideramos que "a memória não é sonho, é trabalho". Se a memória é trabalho, ela implica em movimentos psíquicos de ligações e religações numa nova construção.

${ }^{3}$ Para Larrosa (2002, p. 21), “[...] a experiência é o que nos passa, o que nos acontece, o que nos toca”.

${ }^{4}$ O presente trabalho foi realizado com apoio da Coordenação de Aperfeiçoamento de Pessoal de Nível Superior Brasil (CAPES) - Código de Financiamento 001.

${ }^{5} \mathrm{O}$ professor formador é compreendido como profissional responsável pela mediação da aprendizagem da docência do futuro professor ou do professor atuante em sala de aula (MIZUKAMI, 2005-2006).

${ }^{6}$ Neste estudo "o desenvolvimento profissional e formação entrelaçam-se em um intrincado processo, a partir do qual o docente vai se construindo pouco a pouco" (ISAIA,2006, p.375).

${ }^{7}$ Após o aceite de participação, os professores formadores assinaram a carta de cessão de acordo com os critérios da pesquisa com a história oral (Guimarães, 2006) e os padrões éticos da pesquisa.

${ }^{8}$ Apoiando em Cerezer (2015), considera-se iniciantes os professores com até cinco anos de experiência profissional no magistério.
} 


\section{Wrm

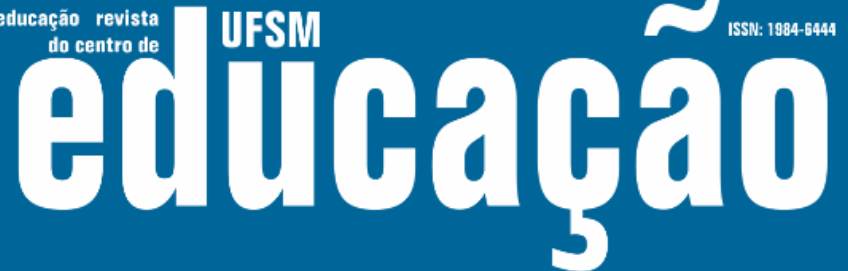

ISSN: 1984-6444 | http://dx.doi.org/10.5902/1984644440380

${ }^{9}$ Os dados foram construídos por meio da análise documental do currículo Lattes dos professores, pontos das entrevistas, das notas no caderno da pesquisa de campo, realizada entre os anos de 2017-2018, nos estados de Rondônia e Tocantins.

${ }^{10}$ Compreendemos que o fazer docente é complexo, histórico e social, o que exige do professor, iniciante ou não, conhecimentos e habilidades que superem uma perspectiva linear de ações e modelos pedagógicos.

11 A partir das ideias de Dubar (2005, p. 23) entendemos, neste estudo, que a “[...] a socialização não é apenas transmissão de valores, normas e regras, mas desenvolvimento de determinada representação do mundo. É um processo de identificação, de construção da identidade, ou seja, de pertencimento e de relação". 